\title{
Una experiencia centenaria de artesanía en piedra: Familia Vergara, canteros de Colina
}

\author{
Elisa Castillo Ávalos* \\ Ángel Roco Videla**
}

RESUMEN:

El presente estudio se enmarca en la recuperación y valorización del Patrimonio Cultural Inmaterial Artesanal, de acuerdo con el compromiso que el Estado de Chile ratificó frente a la Unesco en el año 2007. Nuestra investigación rescata los elementos inmateriales de la cultura en territorios pequeños, en la que la construcción social gira en torno a un oficio artesanal, el que define el modo de ser de los habitantes y sus cultores. Focalizamos nuestra mirada en el caso específico del pueblo Las canteras de Colina, a través de la trayectoria de una de las familias emblemáticas del lugar, los Vergara. Este trabajo está basado en una investigación realizada para UNESCO Chile.

Palabras clave: Patrimonio inmaterial - Artesanía - Oficio tradicional -Cultura local - Minería artesanal.

\section{Uma experiência centenária de artesanato em pedra: Família Vergara, canteiros de Colina}

\section{RESUMEM}

O presente estudo se enquadra na recuperação e valorização do Patrimônio Cultural Imaterial Artesanal, de acordo com o compromisso que o Estado de Chile ratificou frente a UNESCO no ano 2007. Nossa investigação resgata os elementos imateriais da cultura em territórios pequenos, onde a construção social gira em torno ao oficio artesanal, o que define o modo de ser dos habitantes e seus cultores. Focalizamos nosso olhar no caso específico do povoado "As canteiras de Colina", através da trajetória de uma das famílias emblemáticas do lugar, os Vergara. Este trabalho está baseado numa investigação realizada para UNESCO Chile.

Palavras chave: Patrimônio imaterial - Artesanato - Oficio tradicional -Cultura local - Mineira artesanal

* Chilena. Licenciada en Lengua y Literatura hispánicas, Universidad de Chile. Egresada Magíster en Literatura Chileno-Hispanoamericana, Universidad de Chile. Magíster (c) en Educación para el Aprendizaje Transformacional Universidad Bolivariana. Docente Diplomado en edición profesional de la Universidad de Chile. Correo electrónico: elisa.castilloa@gmail.com

** Chileno. Licenciado en Química, Pontificia Universidad Católica de Valparaíso. Licenciado en Educación, Universidad Pedro de Valdivia. Magíster en Educación Ambiental Universidad de Playa Ancha de Ciencias de la Educación. Doctor (c) en Educación para el aprendizaje Transformacional Universidad Bolivariana. Docente de la Universidad Autónoma de Chile. Correo electrónico: angel.roco@docentes.uautonoma 


\title{
A hundred-year old experience of stone craftsmanship: The Vergara family, stone-carvers from Colina town
}

\begin{abstract}
The context of this study is the ratification of the UNESCO Convention for the Safeguarding of the Intangible Cultural Heritage by the Chilean State in 2007. This research tackles cultural intangible elements of small territories where social constructions revolve around a form of craftsmanship that defines the way of being of residents and artisans. This work centres on the case of the Vergara family from Las Canteras de Colina village and it is based on a research conducted for UNESCO Chile.
\end{abstract}

Key words: intangible heritage - craftsmanship - traditional craft - local culture - artisanal mining

\section{Antecedentes}

En la última década, el concepto de patrimonio ha evolucionado desde estar apegado estrictamente al paradigma historicista, estético y monumentalista (Unesco, 1972), hasta integrar la diversidad cultural y el patrimonio intangible en un concepto más preciso, como es el de Patrimonio Cultural Inmaterial, comprendiendo como tal: "los usos y representaciones, expresiones, conocimientos y técnicas (junto con los instrumentos, objetos, artefactos, espacios culturales que les son inherentes) que las comunidades, los grupos $y$ en algunos casos los individuos reconozcan como parte integrante de su patrimonio cultural. Este patrimonio cultural inmaterial que se transmite de generación en generación, es recreado constantemente por las comunidades y grupos en función de su entorno, su interacción con la naturaleza y su historia, infundiéndoles un sentimiento de identidad y continuidad, contribuyendo así a promover el respeto de la diversidad cultural y la creatividad humana" (Unesco, 2003). En este sentido, la reciente conceptualización propone reconocer, poner en valor y realizar acciones de salvaguardia para todas aquellas manifestaciones culturales que se mantienen vivas y se recrean a través de la transmisión directa entre los miembros de las comunidades.

De lo anterior se desprende una clara diferenciación entre lo tangible, representado por los monumentos de la historia humana, y lo intangible, aquello que no tiene la representación física monumental de las expresiones anteriores, pero que constituye la identidad cultural de un territorio, comunidad o sociedad. Ambas miradas son complementarias, puesto que dan cuenta de dimensiones diferentes de una misma realidad, 
lo que implica el resguardo de la cultura tradicional y popular ${ }^{1}$ de cualquier rincón del planeta.

La artesanía es una expresión de la cultura tradicional de una comunidad o territorio. En dicha expresión se funden los conocimientos tradicionales de maestros artesanos, las influencias que reciben del contexto en que habitan y las influencias que la labor artesanal genera en la organización de ese grupo humano: "La naturaleza especial de los productos artesanales se basa en sus características distintivas, que pueden ser utilitarias, estéticas, artísticas, creativas, vinculadas a la cultura, decorativas, funcionales, tradicionales, simbólicas y significativas religiosa y socialmente"2. Las fuentes diversas a partir de las cuales se nutre este conocimiento, son un "resultado (que se gesta) en función del entorno, la naturaleza, la historia y las influencias culturales diversas a las que las comunidades que las producen están expuestas" (Consejo Nacional de la cultura y las artes, 2008). En este sentido, no se trata de una expresión cultural aislada, sino que es un crisol de muchas otras que en su origen no distinguieron entre fines utilitarios, simbólicos y/o mágicos, por lo que es una manifestación que revela dimensiones de una forma de vida, de una identidad determinada. El valor patrimonial de la artesanía no radica en el objeto mismo, sino que en el conocimiento que le da origen, de allí que esta expresión sea considerada una forma de Patrimonio Cultural Inmaterial (PCI).

"Las tradiciones y expresiones orales, incluido el idioma como vehículo del Patrimonio Cultural Inmaterial; artes del espectáculo; usos sociales, rituales y actos festivos; conocimientos y usos relacionados con la naturaleza y el Universo; las técnicas artesanales tradicionales" (UNESCO, 1997), son reconocidas expresiones de la vida cotidiana y espiritual de una comunidad que guardan una profunda e insondable relación con el fortalecimiento de la identidad y su sentido de pertenencia.

1 En este documento se define Cultura Tradicional y Popular de la siguiente forma: "La cultura tradicional y popular es el conjunto de creaciones que emanan de una comunidad cultural fundadas en la tradición, expresadas por un grupo o por individuos y que reconocidamente responden a las expectativas de la comunidad en cuanto expresión de su identidad cultural y social; las normas y los valores se transmiten oralmente, por imitación o de otras maneras. Sus formas comprenden, entre otras, la lengua, la literatura, la música, la danza, los juegos, la mitología, los ritos, las costumbres, la artesanía, la arquitectura y otras artes." Unesco. Primera parte: Artesanía de norte a sur 35. Recuperado el 15 de agosto de 2011. De www.unesco.org/culture/laws/paris/html_sp/ pagel.shtml

2 Esta definición fue adoptada en el Simposio UNESCO/CCI "La artesanía y el mercado internacional: comercio y codificación aduanera", realizado en Manila, entre el 6 y el 8 de octubre de 1997. 
Las características inmateriales de este patrimonio plantean un obstáculo para la investigación y su posterior validación como PCI frente a la comunidad planetaria. De lo anterior se desprende que el registro de cada una de estas prácticas culturales es fundamental a la hora de reconocerlas, ponerlas en valor y realizar las acciones necesarias para su salvaguardia. Este registro, cualquiera sea el soporte en que se realice, no es más que el intento por recuperar momentos en los que la transmisión y/o mantención de una práctica cultural se concretiza en el círculo cercano de quien la realiza, así como en la comunidad en la que habita ${ }^{3}$. Comprender el patrimonio como una construcción social implica también crear las condiciones para la apropiación y revalorización colectiva de estas manifestaciones. El registro riguroso es, entonces, uno de los primeros y primordiales pasos para desencadenar el proceso social de reconocimiento como Patrimonio Cultural Inmaterial.

\section{Desarrollo de la investigación}

Nuestra investigación está anclada en los testimonios de la familia Vergara, quienes han descrito una trayectoria que alcanza cien años en el territorio y cuatro generaciones de maestros artesanos. Cada una de estas voces fue recogida en un intento por iluminar la experiencia de transmisión de este oficio artesanal, valorando la oralidad y sus recuerdos como los vehículos que han permitido tejer su extensa tradición familiar. Intentamos replicar un modo de reconocerse y formar identidad muy antiguo, cual es la tradición oral, instalando en el espacio académico los relatos de los entrevistados que no solo dan cuenta del valor patrimonial de su oficio artesanal, sino que también espejean los hitos de los últimos cien años de la Historia de Chile.

Siguiendo la conceptualización desarrollada por Carlos Huamán, sostenemos que la oralidad es: "Un recurso del que se vale todo ser humano para establecer comunicación y sirve para movilizar cuanto conocemos o anhelamos, individual y colectivamente" 4 . En este sentido,

3 Para García Canclini (1998), las desigualdades en la formación y apropiación del patrimonio demandan estudiarlo como agente cohesionador, pero también como espacio de enfrentamiento y negociación social, como recurso para reproducir las identidades y diferencias sociales, lo que se ha dado en llamar la dimensión política del patrimonio cultural (Bourdieu, 1999), lo que dice relación no solo con la administración territorial de los bienes culturales, sino también con su inclusión en los procesos de apropiación significativa y puesta en valor por la sociedad.

4 Redacción cultura. (2011, 26 de agosto). La oralidad mueve la historia y la memoria. Entrevista a Carlos Huamán. Catedrático de la Universidad Nacional Autónoma de 
reconocemos que la transmisión de la sabiduría y conocimientos del oficio que el maestro artesano comparte con sus aprendices, en un segundo nivel, está basado en la oralidad desplegada durante el desarrollo de la actividad misma ${ }^{5}$. Sin embargo, este íntimo espacio de diálogo comunitario, no tiene representación en otro soporte que le permita ser difundido. Al respecto, Huamán señala: "Pero la oralidad va de la mano con otra manifestación social de representación de nuestra memoria y experiencia: la escritura" ${ }^{\text {. El enfoque }}$ sistémico ${ }^{7}$ que tienen las entrevistas, dan cuenta del efecto que esta actividad artesanal tiene en su propia forma de vida en la esfera de lo público y lo privado; sobre todo en la actualidad, cuando su pervivencia está amenazada por los intereses de la inmobiliarias que han visto en ese territorio un espacio de expansión ideal para su negocio.

La familia Vergara es uno de los clanes familiares emblemáticos del sector de Las canteras ${ }^{8}$. La historia de la fundación del pueblo se remonta a la década de 1930, cuya crisis obligó a muchos canteros a desplazarse hacia otras zonas e incluso a cambiar de oficio. En esa época, una joven mujer, Mercedes Orellana Tapia, que había enviudado recientemente, decidió quedarse en este terreno y apostar por el trabajo con las piedras ${ }^{9}$. Fue así como la actividad atrajo a nuevos canteros, ella se encargaba de comercializar productos, dar pensión y abastecer las necesidades de los obreros en una especie de pulpería que ella misma administraba. De este modo, y así lo han reconocido algunos estudios de la localidad, doña Mercedes fue una figura relevante para el origen del asentamiento que hoy conocemos como

México, especialista en oralidad. Recuperado el 26 de noviembre de 2011. De http:// elcomercio.com/cultura/oralidad-mueve-historia-memoria_0_542345864.html

5 El delicado proceso de la transmisión de maestro a aprendiz ha sido profusamente estudiado por distintas perspectivas de educación popular. Para este trabajo integramos las propuestas de la educación holista que señala: "La práctica del docente holista (requiere de) la totalidad de su subjetividad, de lo que él es está implicado en el proceso educativo". (Gallegos Nava, 2001:233).

6 Ibíd.

7 Este concepto es atraído desde la teoría de la complejidad, que postula que ninguna acción o fenómeno expresado en el contexto de la Vida es aislado e independiente. Edgar Morin es uno de los autores que ha trabajado sobre este corpus teórico.

8 El pueblo de Las Canteras es el lugar donde habita casi la totalidad de los artesanos en piedra del sector, está emplazado en el faldeo norte del cerro Pan de Azúcar, a 16 kilómetros de Santiago, hacia el oriente de la autopista Los libertadores. Esta localidad está compuesta por 393 viviendas aproximadamente, distribuidas en 255 lotes de terreno los que fueron comprados por los canteros a la sucesión don Fermín Vergara Figueroa, hacia 1953 (Garcés, 2008; Puentes, 2010).

9 Esta búsqueda de alternativas económicas para la sobrevivencia es una de las cuestiones sobre las que han teorizado autores como Luis Razeto en su concepto de "economía solidaria". 
pueblo de Las Canteras; incluso, cabes destacar que uno de los cerros con una antigua cantera se llama "cerro La viuda" en su homenaje.

Rolando Abarca, cantero e historiador autodidacta, se refiere a doña Mercedes Orellana Tapia diciendo: “Hay una cuestión con la Señora Mercedes (y es) que entre 1930 y 1932, se fue el 80\% de la gente del pueblo. La única familia que quedó fue la de la Señora Mercedes, no me preguntís por qué, pero ella se quedó. Ella llegó cuando todo el mundo emigró, después de la caída de la Bolsa de Nueva York en $1929^{10}$. Aquí murió su esposo y perfectamente se podrían haber ido, pero decidió quedarse y tirar pa'rriba el trabajo. Todo el pueblo reconoce el valor de la Señora Mercedes, su preocupación por los canteros y el amor que inculcó en todos sus hijos y nietos. Por eso que tenemos el reconocimiento en honor a ella ${ }^{11}$. [...] La familia Vergara en Las canteras ha sido tan importante como la de cualquier cantero, pero tiene a la matriarca, la Señora Mercedes, y eso nadie lo puede negar. El apellido Orellana se ha ido perdiendo, pero ella se identifica como la familia Vergara, si alguien tuviera que hablar de la familia Vergara, tendría que hablar de la Señora Mercedes. Y de hecho yo tengo algo muy especial, que es el libro de cuentas de ella, del año 1936 para adelante, porque ella tenía trabajadores y llevaba un control de todos los movimientos que hacía [...] incluso hay páginas en las que su hijo menor, Antonio, dibujó a la familia trabajando en las canteras".

La señora Mercedes Orellana, no solo fue la abuela matriarca de la familia Vergara, sino que también fue uno de los puntales del nacimiento del pueblo, puesto que al quedarse en Las canteras y convocar a trabajadores para seguir explotando los yacimientos de piedras basálticas, desencadenó la construcción de un campamento y luego, la de series de casas en donde los jóvenes recién casados comenzaban su vida independiente. El tejido social que la abuela generó, también estuvo marcado por su labor como proveedora de los suministros básicos para los trabajadores y sus familias. Su hijo Antonio Torres Orellana, hijo

10 De acuerdo con los testimonios y registros que el propio Rolando Abarca ha recopilado, los canteros del lugar emigraron luego de la crisis de 1929. Muchos de ellos partieron al norte del país buscando nuevas canteras para trabajar y otros tantos abandonaron el oficio para siempre.

11 Desde hace tres años, en la celebración del día del cantero, se hace entrega del premio Mercedes Orellana Tapia a una persona de la comunidad reconocida por su trayectoria en el pueblo. Este reconocimiento surgió a partir de la comunidad y para reconocer a las personas que han trabajado toda su vida en el oficio artesanal del cantero. 
menor de su segundo matrimonio con Fernando Torres, quien vive en el pueblo actualmente, recuerda:

Antonio Torres: "Mi mamá se casó en segundas nupcias con mi papá y yo soy el hijo menor de ese matrimonio. He vivido toda mi vida aquí, aunque estaba trabajando afuera también, pero volví siempre. Cuando yo era niño se trabajaba más que ahora [... ] nos tocaba acarrear agua en los burros para arriba del cerro, ir a buscar las cabras, ir a buscar leña [...] todas esas cosas las teníamos que hacer. Fuimos muy poco al colegio también. Yo fui más porque era el menor y era el más regalón, pero fuimos porros. [... ] Y en la casa había mucho que hacer, porque mi mamá aparte de ser patrona, les hacía comida a la gente que no tenía familia y no tenía donde comer. Entonces ella les daba comida y después se las descontaba del mismo sueldo de ellos. [... I Incluso les hizo un campamento, ahí al lado (de la cantera) para que vivieran los solteros que llegaban a trabajar. Mi mamá era una persona muy humilde y se preocupaba de que los canteros estuvieran bien; incluso a los casados les decía 'llévele un quesito a su señora', porque ella hacía queso de cabra. Fue muy humanitaria mi mamá, porque ninguna patrona le va a estar dando de comer a un trabajador".

De esta manera, la figura de "la viuda", como era conocida doña Mercedes, también ha dejado una impronta muy profunda en su descendencia, que se traduce de manera distinta en cada uno de sus nietos. Estos son algunos de sus testimonios:

Julio Vergara: “La abuela Mercedes Orellana debe haber llegado aquí en los años 20 [...] y en los años 30, cuando vino la gran crisis mundial, la gran crisis económica, los trabajos se pararon, pero ella decidió quedarse aquí y continuar con este oficio, aunque había quedado viuda. Las canteras en aquella época eran el único foco laboral independiente que había en la zona, porque los demás focos de trabajo que habían eran los fundos, era trabajo agrícola. Ese es el valor de mi abuela y eso todos lo reconocen en el pueblo. [...] (Cuando éramos niños) el tío Nacho, y la familia en este caso, con la abuela (Mercedes) que era la cabecilla, se ganaron una parte de la entrega de piedras pa' la construcción del malecón del puerto de San Antonio. Pero las casas (la familia) no se hacían a un lado, sino que el campamento se hacía en la cantera, porque por esa época así era la costumbre. De hecho el pueblo de Las canteras se formó por eso, porque don Fermín Vergara para tener a todos los viejos en un solo lado bajó 
a todos los campamentos que había y les donó esta zanja a las primeras familias. [...] Nuestros papás y nuestros abuelos fueron protagonistas de esto. [...] Por eso yo le dije no todas las familias pueden decir que tienen en su ADN familiar el amor por la piedra. Como familia ejercemos lo mismo que nos trasmitieron nuestros abuelos, porque nuestros abuelos eran los que producían, transportaban e instalaban. Nosotros hemos mantenido eso gracias a la abuela (Mercedes), que es la 'empresaria' que comenzó a tirar pa'rriba a los canteros. Fue una mujer extraordinaria".

Carlos Vergara: "A mí siempre me gustó la piedra. Nosotros pasábamos aquí los fines de semana, porque mi papi jugaba a la pelota, era arquero, así que nos traía todos los fines de semana. Me gustaba venir pa' acá, pa' donde mi abuela porque estaban los cabros y jugábamos a montarnos arriba. De allá arriba (cerro) veníamos a darle agua a las cabras aquí, donde está el puente blanco. [...] Cuando los tíos se ganaron ese proyecto de San Antonio, la abuela Mercedes partió con todos sus nietos y sus hijos, todos estaban vivos en ese tiempo. [.. . ] Ahí la pasamos muy bien, vivíamos como gitanos, pero me gustaba ir a mirar cómo los tíos hacían el trabajo de la piedra y la abuela nos mandaba a mirar para que aprendiéramos".

Juan Vergara: "Independientemente de ser descendiente de ella, que es un beneficio agregado además, pero es lo que ha ocurrido en otras familias, que a lo mejor no conocemos la historia nada más. Ella se nota porque fue patrona mujer, porque los patrones que había eran hombres. Hizo el trabajo de mamá y de patrona. Pero no la siento así como orgullo personal, como descendiente, lo siento como orgullo comunitario, porque la abuela Mercedes es del pueblo de Las canteras, no solo de nuestra familia. [...] A mi abuela la valoro como maestra más que descendiente, como maestra".

La raigambre que el oficio de cantero y la artesanía en piedra tiene en esta familia ha transitado cuatro generaciones, heredando amor y compromiso por estas labores en toda la descendencia, por lo que el trabajo con la piedra forma parte de su identidad. De ahí que la transmisión de los conocimientos y saberes asociados a la actividad artesanal en piedra, es un elemento sustantivo a la hora de entender el trasvasije generacional, la persistencia del oficio mismo y su convicción para proteger el pueblo y su modo de vida. 
Carlos Vergara: "Hay muchas cosas que descubrirle a la piedra. Yo veo una piedra, un trozo grande, y sé qué es lo que puede salir de ahí, a lo mejor yo no lo hago, pero yo le digo al maestro "mira, de ahí vamos a hacer tal pieza" y la hacemos. Eso es lo que me gusta. $[\ldots]$ Yo creo que viene en los genes [...] viene de los papás y los abuelos".

Julio Vergara: "Se ha transmitido en el trabajo. Mirando cómo se hace algo y haciéndolo uno mismo. Todavía hacemos eso con los sobrinos, les damos consejos y les comentamos cosas que les pueden ayudar a hacer la pega para que quede bien, pero ellos aprenden haciendo".

Luis Cancino: "De chico he estado en el rubro de la piedra. Por ejemplo, mis tíos iban a instalar una pileta, o acá en la faena de la pileta, yo estaba ahí con el martillo. Son técnicas que se van aprendiendo con el tiempo, durante años, no es una cosa que uno se siente y te digan, mira esto es así y te centras en una pura parte del proceso hasta que lo aprendes. No, eso va por etapas. Desde chico, cuando iban a instalar las piletas yo iba con ellos, era el que lavaba, el que pasaba la esponja. Esa es la escuela de mi familia. $[\ldots]$ Siempre, siempre me ha gustado la piedra. Yo estudié mecánica pero nunca me gustó. Sigo trabajando la piedra y de eso vivo, de la piedra. Mi papá es agricultor y toda la familia de él igual, todos agricultores, y podría haber seguido ese oficio, era el camino más lógico; pero mi mamá es descendiente de cantero. [...] (Me gusta por) las cosas que se hacen que no las hace cualquiera. En eso va el cariño al trabajo porque no cualquiera toma una piedra y hace una figura, aunque sea insignificante, pero no cualquiera la hace. A mí me gusta mucho este trabajo y me gusta que mi familia entera se dedique a esto".

Este oficio involucra una serie de actividades que implican formas de transmisión de conocimiento, tanto en el modo de vivir como en la organización familiar, asociadas a la actividad productiva de la cantería. En este caso, el patrimonio inmaterial se visibiliza en la transmisión de una serie de valores, conocimientos de oficios y técnicas, y aspectos relacionados con el entorno de esta actividad, todos los cuales son heredados a través de la práctica compartida y de la forma de vida que esta actividad imprime en sus cultores ${ }^{12}$.

12 Sin ser conscientes de los postulados de Edgar Morin (1999), la práctica vital relacionada al oficio que sustentan reafirma estas ideas. 
Juan Vergara: "Nos sentimos distintos (al santiaguino) en hartos aspectos, desde la crianza, hasta la forma que tiene de actuar uno hasta viejo. Bueno, todavía no somos tan viejos, pero hay gente que es vieja y mantiene respeto por los niños. Cosa que en otros lados no lo veo, porque si alguien es pasado a llevar un poquito, saca sus garras en forma inmediata; aquí eso no pasa. Antes se usaba también, inclusive, que papá acusaba al muchacho con el papá de él si veía algún atrevimiento frente a él y el papá algo le hacía".

Julio Vergara: "En este pueblo los viejos viven muchos años y se mueren trabajando o de dueños de casa. No tenemos asilo de ancianos. [...] Las chiquillas que son mamás solteras no son un problema, porque las familias crían a los hijos. [...] Nos conocemos hace muchos años, porque descendemos de las pocas familias que fundaron el pueblo, entonces nos saludamos, sabemos cómo están nuestros vecinos. Si le pasa algo a una familia, la asociación la ayuda. Vivimos de otra manera".

La oralidad y el lenguaje gestual propio del quehacer del maestro cantero, son el principal vehículo de transmisión de este patrimonio. Cabe señalar que entendemos el lenguaje no verbal, gestual o corporal, como una forma de diálogo permanente que mantiene la herencia de esta práctica artesanal en la medida que comunica con claridad una manera de hacer, una técnica específica o la posibilidad de avanzar en una búsqueda personal como aprendiz. En este sentido, el patrimonio inmaterial de los canteros de Colina está constituido por el conocimiento mismo del oficio y su transmisión en una cadena familiar de cuatro generaciones, un siglo de la historia nacional, y su influencia en la comunidad ${ }^{13}$. La estructura familiar misma, los roles que en ella se designan ${ }^{14}$, obedece al influjo que esta actividad ha tenido en ellos y que puede ser considerada patrimonio inmaterial.

13 Junto a Mercedes Orellana, la abuela de este clan familiar, se recuerda la figura de Julio Vergara, padre de los entrevistados, quien fuera Regidor Socialista durante el gobierno de la Unidad Popular, es descrito como un gran organizador comprometido con los destinos de Las canteras. Después del golpe de Estado de 1973, estuvo detenido en el Regimiento Peldehue y al ser liberado no pudo retomar su vida con normalidad. Su hijo Carlos, reconocido maestro artesano, se convirtió en el sostén de la familia.

14 Profundamente patriarcal, los roles sociales en esta comunidad replican el modelo tradicional, dejando el espacio laboral y la participación social y política a los hombres, en tanto que las mujeres se encargan de las labores de casa y la crianza de los hijos. Actualmente, comienzan a agruparse mujeres del pueblo con el fin de desarrollar el oficio artesanal en nichos comerciales que los hombres no han considerado hasta ahora. 
Julio Vergara: “Los tíos Vergara nos enseñaron a trabajar. Para los tíos de nosotros no existía un 'no', o un 'esto no lo puedo hacer', porque lo hacían todo y si no existía la herramienta la fabricaban y si esa cantera estaba apretada buscaban la forma de sacar material de ahí. Entonces reconozco claramente muchos rasgos de la familia nuestra en lo que los demás hermanos Vergara hacemos. [...] (El oficio) Se ha transmitido en el trabajo, mirando cómo se hace algo y haciéndolo uno mismo. Todavía hacemos eso con los sobrinos, les damos consejos y les comentamos cosas que les pueden ayudar a hacer la pega para que quede bien, pero ellos aprenden haciendo. [...] Eso es muy importante, porque no existe escuela para esta cuestión".

Por otra parte, cabe destacar que este oficio tiene distintas etapas en su cadena productiva, lo que ha devenido en distintas especializaciones: canteros o mineros, artesanos e instaladores; todas las cuales son desarrolladas por los integrantes de la familia Vergara. De esta manera, no se trata solo de la transmisión patrimonial del oficio, la técnica y el modo de producción en sí mismo; sino que también la forma en que constituyen relaciones de trabajo que comprenden estructuras de pensamiento únicas debido a las características del territorio, del oficio artesanal y de las circunstancias en que se desarrolla.

Julio Vergara: "Nosotros aprendimos de chicos a trabajar en todas las partes que se relacionan con el trabajo de la piedra. El punto de encuentro nuestro siempre, en todos los trabajos, es que cada uno en su sector aporta a que el producto sea mejorado. Independientemente de si el trabajo es de Carlos, es de Juan o mío, cuando necesito un producto que es de taller, como por ejemplo una fuente, lo hace Carlos, así como cuando Carlos necesita un pilar como ese lo hace Juan. Cuando Carlos necesita una opinión con respecto a cómo se puede construir algo, cuenta con mi opinión [...] Eso también es herencia de nuestra familia. El desarrollo de la familia, y eso es idea de la abuela Mercedes, siempre ha estado en la producción, de hacer el proceso completo. Eso lo hemos mantenido nosotros. Somos una de las familias que no se ha quedado estancada en un sector del proceso. Cuando Carlos recibió la primera invitación a la feria de artesanía $^{15}$, me preguntó qué pensaba yo... le dije que participara

15 Alude a la Muestra Internacional de Artesanía Tradicional organizada por la Pontificia Universidad Católica de Chile, a la que Carlos Vergara ha asistido en sus últimas versiones. 
y los ayudamos a llevar las cosas para allá, nos amanecíamos cargando el camión".

La especialidad de los canteros, o mineros, es la de aquellos que trabajan directamente en la cantera, extrayendo las piedras del cerro. Son los encargados de sacar los bloques de piedra del cerro y luego recortarlos al tamaño que les solicitan o el que requiere el mismo maestro para un producto determinado.

Carlos Vergara: "En cuanto al trabajo en la misma roca viva, soy el que tengo más capacidad y experiencia pa' cortar la piedra y de ir a la fragua, cortar el fierro y hacer las herramientas. Tengo todo ese conocimiento y lo hago rápido".

La instalación corresponde al trabajo de colocación de los productos de piedra, ya sea los traídos del cerro o aquellos elaborados en los talleres de artesanos del pueblo. Esta especialidad está abocada a la ornamentación pública, pavimento, revestimiento y mobiliario urbano, lo que se traduce en la instalación de adoquines, cobertura de muros, instalación de piletas, entre otras, por lo que esta labor depende de las anteriores.

Julio Vergara: "Soy instalador y constructor, aunque conozco y he trabajado en las distintas partes de todo el proceso de la piedra, porque me gusta ver la piedra transformada en construcciones, como ser en plazas, en calles, etcétera".

Carlos Vergara: "Elías, el otro hermano, también tiene su especialidad que es colocar la piedra en el muro. Ve la piedra, la toma, la mira y la coloca ahí [... t tiene esa habilidad y es rápido en su trabajo".

Los artesanos son aquellas personas que trabajan en los talleres del pueblo de Las canteras, fabricando pilares, piletas, asientos, mesas, objetos utilitarios y algunas esculturas.

Juan Vergara: "Yo me dedico a terminar bien la pieza, porque me gusta que queden bien pulidas [...] me gusta trabajar con las texturas de la piedra y los colores que tiene, porque los bloques de piedra no son parejos [...] incluso me gusta que queden suaves al tacto. Por eso trabajo en el taller, aunque sé hacer lo demás, esta parte del trabajo es la que más me gusta".

Una caprichosa característica de esta labor artesanal es que recae exclusivamente en los hombres del pueblo, dejando a las 
mujeres a cargo de la crianza de los hijos e hijas, y del cuidado de la casa, en la mayoría de los casos. Sin embargo, la valoración que las mujeres de la familia hacen de esta labor es rotunda y satisfactoria:

María Cubillos: "La piedra es todo. Vengo de una familia de canteros y me casé con un cantero, aunque él después trabajó de chofer en la $\mathrm{ETC}^{16}$, pero nunca dejamos de ser canteros. [...] Fui criada con el trabajo de la piedra, crié a mis hijos y ahora mis nietos viven de lo mismo".

Marianela Vergara: "A nuestra familia la piedra le ha dado todo, desde la abuelita Mercedes hasta ahora. Me siento orgullosa de que mi familia se dedique a esto y espero que mi hijo sea un escultor algún día y que trabaje con la familia. | ... | Mi sueño sería poder armar una empresa familiar y yo dedicarme a la venta de los productos que ellos hagan. Con Carlos siempre conversamos que nos gustaría poner una escuela para formar canteros. Ese es otro sueño que tengo".

En los últimos años este sector ha sufrido el agresivo incremento del desarrollo inmobiliario, el que no ha considerado el valor del trabajo de los artesanos en piedra. El territorio se ha poblado de exclusivos condominios, los que han modificado la vida de los habitantes y la geografía del terreno para siempre. El trabajo de los canteros se ha visto alterado debido a que tienen problemas para acceder a la cantera y se encuentran restringidos a una cada vez más pequeña porción de terreno.

Julio Vergara: "Las inmobiliarias nos han rodeado. A pesar de que tenemos la pertenencia minera, han construido sobre los terrenos que podemos explotar para nuestro trabajo. Ahora para ir a trabajar a las canteras tenemos que pedir permiso al guardia del condominio $[\ldots]$ Creo que quieren que nos vayamos de aquí".

Este modo de vida se ha visto cada vez más restringido y atacado por los cambios sufridos en el entorno natural en que viven, lugar que proporciona la materia prima para su actividad. Esta es una preocupación que la familia Vergara comparte con toda

16 El padre, Julio Vergara, fue empleado público en el cargo de chofer de la ETC. La ETC fue la Empresa de Transportes del Estado, organización perteneciente al área de empresas sociales del gobierno de la Unidad Popular. La actividad del transporte fue considerada como un sector estratégico para el gobierno de Allende y por eso decretó que existirían tipos de propiedad de las empresas transportistas. La ETC era una empresa estatal, por lo que sus trabajadores eran funcionarios públicos. 
su comunidad, puesto que ven amenazado no solo su sistema de vida, sino que la subsistencia de un trabajo artesanal vinculado íntimamente a la historia de nuestro país. En el caso de la construcción de condominios sobre un terreno destinado a la explotación de la minería artesanal, la asociación de canteros ha recurrido a los tribunales para aclarar el conflicto. Sin embargo, la situación aún no se resuelve en su favor, aunque constan en su poder los documentos que legitiman su dominio sobre la extensión de terreno que delimita la pertenencia minera vigente.

Rolando Abarca: "Lo que pasa es que la plusvalía de los terrenos en este minuto es muy alta. Los terrenos más caros de Chile están aquí y por eso las inmobiliarias llegaron. Nosotros no hemos sido capaces de darnos cuenta de toda la vorágine económica que hay en toda esta cuestión, ellos tienen plata para comprar todo lo que quieran comprar. Eso es de lo que no se da cuenta la gente, nosotros estamos luchando como David contra Goliat, tienen los mejores abogados de Chile, los mejores bufetes, y nosotros tenemos un abogado con un ayudante. Pueden haber muy buenas intenciones, pero la justicia no funciona muchas veces con buenas intenciones".

Un modo de proteger y resguardar el valor patrimonial de esta actividad y el pueblo mismo, ha sido la presentación al Consejo de Monumentos Nacionales de la solicitud para declarar a Las canteras zona típica, categoría que les proporciona visibilidad pública y los protege del apetito voraz que las inmobiliarias tienen por los terrenos en los que se encuentra el pueblo y en los cerros donde van a extraer rocas. La presentación fue aceptada por el Consejo y se encuentra en espera de la firma del Ministro de Educación para que se concrete como ley de la República. Rolando Abarca ha sido uno de los movilizadores del proceso de formación del expediente para la postulación de Las canteras al estatus de Zona Típica protegida. Recuerda el proceso y su problemática tramitación señalando:

Rolando Abarca: “Todo esto nació con el centro cultural 'Raíces de piedra'. Se formó hace tres años y es una iniciativa de un grupo de chiquillas, dentro de ellas está mi señora, que tenían la inquietud de hacer cultura en Las canteras, traer artistas, etcétera, y como la Junta de vecinos era lejana a nosotros, porque la junta de vecinos estaba intervenida por la Mónica Madariaga, entonces el centro cultural se formó independiente y empezaron a comunicarse con 
gente de otros lados. Así llegaron al Barrio Yungay, donde hay un movimiento cultural enorme y ellos llegaron aquí cuando tenían como cinco meses de que los declararan Zona típica; con ellos fuimos intercambiando información y decidimos postular. Ahora, cuando nosotros postulamos nos dimos cuenta que no tenemos nada tangible, solamente se nos ocurrió una cantera y postulamos con eso, después empezamos a tirar información de las costumbres, de todo lo intangible. La presentación oficial se hizo el 10 de marzo de 2009. La lucha que dimos nosotros para que se reconociera nuestro pueblo como Zona típica protegida fue enorme, porque no es que el Consejo nos quisiera rechazar, sino que teníamos que ir contra las bases, había que hacer algo que fuera en contra de lo que estaba establecido, porque el Consejo no tiene considerado este tipo de cuestiones. De hecho el Cuasimodo de Colina, para poder declararlo patrimonio, tuvieron que tomar una montura y un par de espuelas. [...] Entonces, como no teníamos casi nada, empezamos a tirar información. Ahí creo que jugué una parte importante, humildemente lo digo, porque yo tengo mucho escrito (de la historia de Las canteras), empecé a hacer resúmenes de eso y a mandárselos a los consejeros personalmente. Les puedo mostrar una carta que le mandé a cada uno de ellos, diciéndoles por ejemplo, que los canteros por esencia somos rudos e independientes, pero necesitamos alguien que nos proteja frente a esta situación. ¿Y quién mejor que el Consejo? Ahí les empiezo a explicar que nosotros toda la vida hemos entregado nuestro trabajo a sangre y fuego, para que los otros sean reconocidos. Eso les llegó justo a los consejeros, porque después me lo comentaban. Después nos tocó ir y exponer, y nos dimos cuenta de que el día clave que nosotros teníamos que jugárnosla era el día de la exposición allá, porque ellos no tenían sobre la mesa cosas sólidas como para decidir. [...] porque no iba a faltar el que no iba a estar de acuerdo, el que iba a decir hay casitas como en todas partes. Entonces, lo que teníamos que hacer era convencer a los que no estaban de acuerdo. Yo llevé un video de unos niños chicos que trabajan, que en vez de jugar con autos, juegan con la piedra. Fuimos a las tres de la tarde y a las dos de la tarde me llamaban los consejeros preguntándome, oye los adoquines de tal calle, ¿los hicieron ustedes o los hicieron los canteros de Santiago? Les decía que daba lo mismo, porque los canteros de Santiago y nosotros somos de una misma familia, si nos cambiamos de lugar no más. Eso los hacía a ellos recapacitar. Para sorpresa de nosotros, nos declararon Zona típica. Después fui a una reunión en el Consejo 
de Monumentos y el presidente me dice que necesitaban un ciudadano para que fuera parte de los consejeros. Ahí me tocó decirle que con lo que había pasado qué sentido tenía que un ciudadano se sentara ahí, si el voto de ellos no vale, porque es el ministro el que decide. Tienen 21 consejeros, cada uno estudia el caso, se compromete y después viene el ministro y les dice que no, entonces no tiene sentido. Y de ahí se agarraron los demás, porque lo que pasa es que mandaron nuestra declaratoria al Consejo de Defensa del Estado, el Ministro Lavín ${ }^{17}$ no fue capaz y se lavó las manos, dijo 'yo no puedo deliberar, llévenlo al Consejo de Defensa del Estado y lo que él diga'; y el Consejo de Defensa del Estado dice que sí, que firme por favor. En este minuto está en manos del Consejo de Defensa del Estado, que yo encuentro que es mucho, porque está para otra cosa. El Consejo de Defensa del Estado le ahorra al gobierno el 93 por ciento de las platas que demandan al gobierno; o sea, si cien personas demandan al gobierno, ganan siete, porque está para eso, para expropiar y para hacer un montón de cosas".

\section{Reflexiones finales}

Frente a los datos previos sobre la existencia de Patrimonio Inmaterial en el pueblo de Las Canteras de Colina, nos hemos sorprendido con que existen muchas más representaciones de cultura inmaterial que resguardar que merecen un estudio pormenorizado y particular en cada caso. El espacio sobre el que se desplegó el trabajo sorprende en riqueza cultural y la mantención de prácticas variadas asociadas al trabajo artesanal con roca basáltica.

La comunidad se mostró siempre muy dispuesta a colaborar con nuestro trabajo y, al mismo tiempo que tomaban conciencia del valor del patrimonio que poseían, generaban expectativas futuras respecto de la salvaguardia de su estilo de vida.

En este sentido, los testimonios y registros de distinta naturaleza compartidos por los propios artesanos y sus familias con los investigadores de este estudio, no solo buscaban recomponer el relato de su existencia y señalar sus marcas de identidad, sino que confiaban en que nuestra labor visibilizaría su compleja situación en espacios a los que aún no habían llegado, convirtiéndose en

17 Joaquín Lavín, Ministro de Educación durante el periodo en que se tramitó la declaratoria de Zona típica. 
una vía de difusión de sus acciones para mantener su tradicional modo de vida.

El patrimonio inmaterial que constituye esta actividad y la situación vital de la comunidad que lo sustenta (Bourdieu, 1999; García Canclini, 1999), merecen un reconocimiento y cuidado de la sociedad chilena en su conjunto, pues en estas manifestaciones se encuentran las señales inequívocas de una identidad que nos pertenece, de una práctica que también es una estética que conforma nuestro arte popular y de la construcción que cimentó las capitales del país y todas sus instituciones.

Los canteros de Colina, y específicamente la familia Vergara, son la muestra viva de que este oficio no solo está vigente, sino que evoluciona con los tiempos y busca caminos para incorporarse al progreso social de su comuna sin perder su origen y trascendencia, el valor de su identidad.

La palabra, con toda la fe y esperanza que contiene, sigue transmitiendo su secreto fuego a las nuevas generaciones de artesanos canteros en el pueblo de Las canteras, en Colina.

\section{Bibliografía}

Bourdieu, P. (1999). La distinción. Criterio y bases sociales del gusto. Madrid: Edit. Taurus.

Consejo Nacional de la cultura y las artes (2008). Chile Artesanal, Patrimonio Hecho a Mano. Disponible en http://www.memoriachilena.cl/archivos2/pdfs/ MC0053875.pdf

Gallegos, R. (2001). Educación holista. Pedagogía del amor universal. México: Fundación internacional para educación holista.

Garcés, M. (2008). El patrimonio cultural en Las Canteras de Colina: una reflexión social en torno a su preservación. (Tesis para optar al título profesional de Antropólogo Social). Santiago: Universidad de Chile.

García Canclini, N. (1998). Cultura y Comunicación en la Ciudad de México. Primera Parte: Modernidad y multiculturalidad: la ciudad de México a fin de siglo. México DF: UAM/ Grijalbo.

García Canclini, N. (1999). "Los usos sociales del Patrimonio Cultural”. En Patrimonio Etnológico. Nuevas perspectivas de estudio ( $1^{\text {a }}$ edición, p. 16-33). España, Aguilar Criado, E. 
Morin, E. (1999). Los siete saberes para la educación del futuro. París: Unesco.

Unesco (1972). Convención sobre la protección del patrimonio mundial cultural y natural. París: Unesco.

Unesco (2003). Convención para la Salvaguarda del Patrimonio Cultural Inmaterial. París: Unesco.

Ministerio de Vivienda y Urbanismo, programa Quiero mi Barrio (2010). La piedra respira: Las Canteras de Colina. Santiago de Chile: Impreso en Crea2.

Huamán, C. (26 de agosto 2011). La oralidad mueve la historia y la memoria. El Comercio.Com. Disponible en http://elcomercio.com/cultura/oralidad-muevehistoria-memoria_0_542345864.html 